\title{
UM DIÁLOGO ENTRE A VIDA REAL E A LITERATURA INFANTOJUVENIL: UMA EXPERIÊNCIA DE LEITURA NA PERSPECTIVA DA PRODUÇÃO DE SENTIDOS
}

\author{
UN DIALOGO ENTRE LA VIDA REAL Y LA LITERATURA \\ INFANTO-JUVENIL: UNA EXPERIENCIA DE LECTURA \\ EN LA PERSPECTIVA DE LA PRODUCCIÓN DE \\ SENTIDOS
}

\author{
Lucas Veras de Andrade * \\ Ana Caroline Viana de Melo**
}

\begin{abstract}
RESUMO:
Introdução: Ao longo do tempo, o termo leitura vem sendo conceituado de forma polissêmica e seu significado depende do enfoque a ser compreendido. No estudo, tem-se como foco a perspectiva conciliadora. Nesta, texto e leitor estão em constante interação. Assim, ler é interagir com o texto, produzir significados. Partindo desta acepção, é que buscamos em nosso estudo uma interlocução com a técnica da biblioterapia, compreendida como uma terapia por meio de livros.
\end{abstract}

Objetivo: Ressignificar o processo de adoecimento de uma paciente oncológica infantil por meio da biblioterapia, de modo a desfocalizar a doença com a inserção do lúdico por meio da literatura infanto-juvenil.

Metodologia: A pesquisa tem o caráter qualitativo, sendo classificada quanto aos procedimentos como Pesquisa-Intervenção. Possuindo características descritivas e associada ao método cartográfico. Tendo como protagonista, uma criança do sexo feminino (11 anos), diagnosticada com uma neoplasia pélvica de caráter maligno, em estágio avançado. Utilizou-se ainda, o desenho como promotor de diálogo entre os profissionais envolvidos na intervenção e a paciente.

Resultados: A leitura proposta permitiu nossa interlocutora não só vivenciar sua história a seu modo, como também ressignificá-la.

Conclusões: Podemos finalizar assim, colocando em foco que já não somos os mesmos, e sim outros de nós. Provocados por alterizações produzidas em cada encontro realizado.

*Professor das Séries Inicias da Educação Básica da Secretaria Municipal de Educação de Teresina. E-mail: lukkandrade18@hotmail.com

**Especialista em Saúde Mental e Atenção Psicossocial. E-mail: carolinevmlu@yahoo.com.br. 
Palavras-chave: Alice no País das Maravilhas. Biblioterapia. Literatura Infanto-juvenil. Método Cartográfico. Pesquisa-Intervenção.

\section{PARTINDO PARA UM TERRITÓRIO EXISTENCIAL: A LEITURA E OS SENTIDOS}

Ao longo do tempo, o termo leitura vem sendo conceituado de forma polissêmica e seu significado depende do enfoque a ser compreendido. Temos o sentido generalista, onde ler atrela-se a concepção de alfabetização e letramento. Por esta ótica, a compreensão da linguagem oralizada dar-se por meio da escrita e a função social dos textos (ALBUQUERQUE, 2007). Temos ainda duas acepções antagônicas. A primeira, ler é extrair significado do texto. Logo após, ler é atribuir significado ao texto. O antagonismo de ambas está na oposição dos verbos extrair e atribuir. Ao se usar o verbo extrair, dá-se mais importância ao texto. "Usando o verbo atribuir, põe-se a ênfase no leitor" (LEFFA, 1996, p. 11). Por fim, um conceito conciliador no qual texto e leitor não estão em lados opostos, mas em constante interação. Nesta perspectiva, ler é interagir com o texto. Produzir significados.

Partindo desta última acepção de leitura, é que buscamos em nosso estudo uma interlocução com a técnica da biblioterapia. Biblioterapia pode ser compreendida como uma terapia por meio de livros ou qualquer meio lúdico. Que intenciona promover no indivíduo em processo terapêutico, o ressignificar de uma problemática, seja ela: psicológica, social ou cultural. Nesta perspectiva, a leitura intrínseca ao processo biblioterápico visa desvelar horizontes de significados atribuídos pelo paciente. Assim, o indivíduo se constrói a cada leitura. Não emergindo no processo, o sentido dado pelo autor das obras ou textos. Mas novas possibilidades de sentidos associadas ao conflito problematizado no processo de intervenção.

Desse modo, transmitidas as informações que permitam uma noção breve do que pretendemos, delimitamos a intenção do trabalho na leitura acima, aliada a biblioterapia, juntamente ao paciente infantil oncológico. A proposta parte de uma experiência pessoal dos pesquisadores, que pela formação acadêmica foram convidados ao convívio e a buscar a reflexão de 
uma enferma sobre o cotidiano e a vivência de uma neoplasia maligna em estágio avançado. Assim, temos como objetivo geral: Ressignificar o processo de adoecimento de uma paciente oncológica infantil por meio da biblioterapia, de modo a desfocalizar a doença com a inserção do lúdico por meio da literatura infantojuvenil.

Uma vez demonstradas nossas intenções, o texto foi estruturado em tópicos nos quais no primeiro, apresentamos uma breve contextualização da temática de estudo. No segundo, descreveremos a leitura na perspectiva da produção de subjetividade, enfocando a biblioterapia. De modo, a evidenciar o conceito e função no contexto oncológico infantil, entre outros aspectos.

No terceiro, temos o percurso metodológico. Neste, apresentamos o caminho delineado, no sentido de darmos conta do objetivo estabelecido. Logo após, temos as análises e discussões que descrevem empiricamente 0 processo interventivo. E por fim, as considerações finais que trazem um olhar holístico sobre todo o processo e apresentamos os principais achados. Assim como, apontamos algumas sugestões para o trato de algumas questões que emergiram no decorrer do percurso de intervenção.

\section{A LEITURA NA PERSPECTIVA DA PRODUÇÃO DE} SUBJETIVIDADE: UM ENFOQUE SOB A ÓTICA DA BIBLIOTERAPIA

Para a realização do processo da biblioterapia, partimos do pressuposto da subjetividade como algo que está em movimento. Em um devir. Não a tratamos como algo acabado e pronto. E sim, falamos de processo que pode sofrer influências múltiplas e provocar alterização"

Buscamos então, a conceituação de Guattari (1992) na qual as subjetividades são produzidas por agenciamentos coletivos de enunciação. Este autor propõe que cada sujeito também é produtor de subjetividade. Deste

\footnotetext{
${ }^{1} O$ termo alterização é polissêmico. E a compreensão depende do escopo de estudo. Aqui a noção pretendida, parte da Psicologia Histórico-Cultural. Nela, a ideia deste conceito, parte da concepção de movimento, onde o indivíduo em um devir, desenvolve um olhar diferente sobre uma mesma coisa. Torna-se outro de si mesmo. Para aprofundar a discussão, ver Zanella (2005).
} 
modo, esta é produzida por instâncias individuais, coletivas e institucionais que se dão na constituição de complexos de subjetivação: indivíduo-grupomáquina-trocas múltiplas. Que oferecem à pessoa um leque de possibilidades que permitem recompor uma corporeidade existencial. Sair dos seus impasses que provocam a repetição. E de alguma forma, ressingularizar-se.

Dimenstein (2000, p. 116) reafirma essa ideia ao dizer que "a subjetividade é um fato social construído a partir de processos de subjetivação. O qual é engendrado por determinantes sociais - históricos, políticos, ideológicos de gênero, de religião, conscientes ou não". Acreditamos desse modo, que o processo realizado na exploração da obra literária por meio da biblioterapia, vem trazer para os pacientes alguns questionamentos acerca de sua situação, do enfrentamento de suas problematizações. No tratamento, a leitura ou somente a escuta da obra, vem como forma de provocar novas concepções de ser e estar no mundo.

Dessa maneira, a leitura permite a cada leitor inferências pessoais, atribuição de sentidos próprios que se dão através da interação dialética entre autor/leitor por meio do texto. Os quais se expressam de modos singulares na perspectiva subjetiva de cada leitor. Neste sentido, pode-se dizer que há uma reconstrução do texto a cada leitura, já que não há em si um sentido preestabelecido pelo seu autor. "E sim a possibilidade de várias significações estabelecidas por aquele que ler ou ouve as narrativas". (FERREIRA; DIAS, 2004, p.439). Ou seja, cada leitor atribui uma significação própria à sua leitura.

A biblioterapia permite desse modo, o envolvimento emocional com a narrativa e a aplicação do que se leu a própria vida. Neste sentido, o terapeuta poderá atuar como mediador oferecendo auxílio na mediação dos conteúdos e na sua interpretação (VALENCIA; MAGALHÃES, 2015, p.7). Ainda segundo o autor:

Este processo no contexto oncológico infantil por meio do lúdico, permite ao paciente um distanciamento daquilo que lhe provoca sofrimento e a possibilidade de rever conceitos, redesenhar imagens, redescobrir emoções, tomar decisões, escolher caminhos. Colocar nesse sentido em atividade o pensamento e a imaginação. Ou seja, "unir a percepção subjetiva à vida prática, construindo uma sensação libertadora 
para o ser envolvido nesse processo terapêutico" (VALENCIA; MAGALHÃES, 2015, p.7, grifo do autor).

Assim, o processo de interação entre o paciente e a obra lhe possibilita um momento de distraibilidade. Que o permite distanciar-se mesmo que por alguns instantes daquela situação de sofrimento. Podendo este, trabalhar suas emoções a partir da identificação com os fatos lidos ou mesmo narrados pelo biblioterapeuta. Acreditamos neste sentido, que esta seja uma oportunidade para a ocorrência de produções, ressignificações do momento vivido pelo paciente.

\section{O CAMINHO TRILHADO}

A pesquisa tem o caráter qualitativo, sendo classificada quanto aos procedimentos como Pesquisa-Intervenção. Possuindo características descritivas e associada ao método cartográfico. Entende-se por pesquisaintervenção, uma tipologia de "pesquisa que não dissocia o objeto investigado ao sujeito que a investiga [...]" (PAULON; ROMAGNOLI, 2010, p. 95). A configuração da pesquisa dialogando com a cartografia, deu-se a medida que os pesquisadores decidiram por imergir no mundo da interlocutora do estudo e delinearam sua vida, especificamente o adoecimento oncológico a partir do plano das sensações e do invisível, como objeto a ser problematizado. A cartografia neste sentido, nos possibilita um desenhar, num processo mediante passos, acompanhar este processo.

Outro aspecto que embasa nossa escolha por associar a cartografia em nossa intervenção, é o fato dela conferir ao pesquisador a possibilidade de criação de zonas de indagações, que oportunizam o aflorar de um coletivo. $\mathrm{Na}$ contextualização de nossa intervenção, estas são compreendidas como um plano de co-engendramento em que dicotomias do indivíduo e da sociedade não têm lugar (ESCÓSSIA; KASTRUP, 2005). A intervenção ainda contou com a biblioterapia, que assim como a cartografia, possui em seu âmago a alteridade, a problematização e a transversalização do campo de análise. 
Nesse sentido, o percurso de intervenção teve como protagonista uma criança do sexo feminino, de 11 anos. Diagnosticada com uma neoplasia pélvica de caráter maligno, em estágio avançado. Este foi dividido em dois momentos, compreendido por pistas. Um inicial, onde se utilizou jogos, observação, escuta e diálogos reflexivos. No intuito de buscarmos uma aproximação com a interlocutora e com isso, provocar a enunciação de discursos sobre medos, desafios e o conviver com o adoecimento em sua rotina.

Nesta situação, começou-se a delinear as primeiras forças circulantes. Pensamentos do tipo: "O porquê comigo?", foram os produtos mais frequentes neste momento produzidos pela criança. Com isso, fomos produzindo os primeiros contornos, a partir dos pontos de insurgências dos devires externados.

A partir também deste momento, e por enxergarmos a necessidade constante de um suporte para criança, nos desprendemos do tempo fixo para a finalização da intervenção. Pois pela devolutiva do contato inicial, entendemos que os discursos ali produzidos seriam uma constante produção e objeto também de reconstruções. Conferindo neste percurso, a ideia de algumas das pistas do método cartográfico como: Cartografar é acompanhar um processo e não representar um objeto e Cartografar é habitar um território existencial (BARROS; KASTRUP, 2015), entre outras.

No segundo momento, contamos com o auxílio da biblioterapia, tendo por base a obra Alice do país das Maravilhas, de autoria de Lewis Carroll (2014). Assim como, a obra cinematográfica adaptada, de Tim Burton (2010). Ainda nesta intervenção, solicitamos a produção de desenhos e desenvolvemos uma narrativa em um diário de campo. Sendo todos os discursos produzidos e categorizados a partir de eixos temáticos, mediante cenas do filme. E analisados na perspectiva da análise de conteúdo (BARDIN, 2011). 


\section{A SUBJETIVIDADE E A PRODUÇÃO DELA A FLOR DA PELE: INTERSECÇÃO ENTRE A OBRA E NOSSA INTERLOCUTORA}

Aqui cabe apontarmos a compreensão admitida no estudo dos termos que acima apontamos. E que embora parecidos, são distintos em suas semânticas. Assim como, apresentar em seguida, um recorte a partir de três encontros sobre as reflexões de nossas narrativas sobre os grafismos produzidos no processo de intervenção em nosso diário de campo (de um percurso de seis meses com nossa protagonista).

Desse modo, subjetividade além dos conceitos já apresentados, a compreendemos também na perspectiva da psicologia sócio-histórica. Especificamente, na teoria de Leontiev (1978). Na compreensão dada por ele, é algo constitutivo e pertencente ao indivíduo. De modo, que este pertencimento se torna singular.

Já a produção de subjetividade está pautada nos estudos de Félix Guattari (1992; 1993) que de forma breve, define as diversas formas de ver, sentir e estar no mundo. Uma vez apresentadas as teorias que embasam o trabalho, a seguir, abordaremos a intervenção propriamente dita.

Após o primeiro encontro com a paciente, solicitamos que esta desenhasse algo que representasse aquele momento. Ela por sua vez, realizou um desenho fazendo uma leitura bem subjetiva da situação. Principalmente no que se refere às suas emoções na representação da própria imagem. Esta realizou um desenho fiel ao posicionamento dos terapeutas e ao seu diante das atividades propostas e a vivência deste momento inicial. Colocando-se deitada e com uma expressão facial que denotou a presença de emoções negativas a seu respeito.

Percebe-se que o desenho fez emergir a autoimagem da criança e características de sua doença (perna esquerda encurtada, ausência de cabelos e rosto abatido). Desconsiderando assim, a sua imagem anterior ao processo de adoecimento. Outro aspecto a ser levado em consideração foi a falta de interesse da paciente em colorir o desenho. Que pode ser inferida como uma desmotivação em virtude de dar cor, a uma representação ausente. Trazida 
pelas possíveis emoções negativas evocadas, ou mesmo pela condição física que a cada encontro mostrava-se mais debilitada.

No segundo encontro, solicitou-se um grafismo após a mediação de leitura de um capítulo da obra já mencionada. A paciente realizou a representação da personagem da história que Ihe foi contada deitada em uma cama. Tal qual estava a representação de sua imagem na atividade anterior. $\mathrm{O}$ proposto nesse desenho seria uma imagem que representasse uma cena que chamou sua atenção na história. Esta, o fez de forma a transpor-se ao mundo imaginativo e se pôs como a personagem Alice, protagonista da obra supracitada.

Neste momento, percebemos que nossa interlocutora conseguiu projetar-se na personagem e desvirtuar-se de suas queixas. Já que em nossos encontros, por sua condição bem fragilizada, a paciente se encontrava sempre queixosa. Às vezes com dores e outros sintomas que acompanham a doença.

Em nossa terceira atividade e última a ser analisada, inserimos no contexto a cinematografia, com a obra homônima adaptada de direção de Tim Burton. Esta foi assistida na íntegra, e ao término, exibimos imagens que a representavam. Havendo com isso, uma proposta de relacionar e refletir trechos do filme a história da paciente. Um destes trechos trazia 0 questionamento da personagem em enfrentar um grande desafio. Neste momento, ao relacionarmos a narrativa com a história da paciente, a mesma trouxe diretamente emoções como medo e tristeza. Percebemos que este foi um espaço para catarse, ocorrida a partir da situação proposta. Esta pôde verbalizar angústias que se encontravam resguardadas, proporcionando-lhe a possibilidade de aliviar as tensões ali presentes.

Assim: "Embora o texto carregue um sentido pretendido pelo autor, ele é polissêmico e, como tal oferece possibilidades de ser reconstruído a partir do universo de sentidos do receptor" (FERREIRA; DIAS, 2004, p.440). Nesta perspectiva, o receptor da narrativa negocia os significados dando a estes, coerência a partir da intencionalidade que o mediador estabelece no processo biblioterápico. Assim, houve inúmeras escutas, problematizações por meio da literatura e o direcionamento destas para o caminho da superação de mal- 
estares emocionais e pontuais causados pelo processo de adoecimento. Neste momento, a paciente contou ainda com o apoio psicológico e assessoramento de um profissional da psicologia.

\section{CONSIDERAÇÕES FINAIS}

Na pesquisa, trabalhamos na perspectiva do desejo. Nesse sentido, a mudança almejada no processo interventivo não se fez pela conscientização do outro. Ou seja, de nossa interlocutora. Mas a pretensão era que este aspecto se estabelece por contágio. Mas o que seria o contágio?. Segundo Paulon e Romagnoli (2010), seria a potencialização da vida. Significar a vida como um modo de existência constante. Pois entendemos que a psique humana não lida apenas com o que o indivíduo é, mas também com o que ele pode ser.

Pelos dados da intervenção ainda estarem em análise, de forma breve, podemos afirmar que a leitura proposta permitiu a nossa interlocutora não só vivenciar a sua história a seu modo, como também ressignificá-la. Na medida em que enquanto terapeutas, a direcionamos a refletir o comportamento e as saídas encontradas pela personagem da obra aqui exposta para seus medos e angústias. De forma, a introjetar-se nela.

Cabe ressaltar que a escolha das obras a serem utilizadas devem estar associadas as temáticas a serem enfocadas, assim como todo o processo biblioterápico deve ser cautelosamente estudado em todas as suas etapas. A obra escolhida nesta intervenção em específico partiu da própria paciente, o que facilitou uma melhor identificação, projeção e catarse dela via personagem. Por fim, finalizamos este estudo tristemente, uma vez que o desfecho de nosso enredo terminou com o óbito de nossa personagem principal. Cabendo a sugestão da psicoterapia para os profissionais que queiram desenvolver intervenções como a descrita, já que o aspecto morte é uma possibilidade.

Nós terapeutas e pesquisadores, também fomos atravessados por diversos afetos. Sendo estes, ora positivos (pela satisfação de poder ter acolhido alguém que passava por uma situação de sofrimento), como também negativos (ao nos depararmos com o agravamento do quadro da paciente, momento no qual buscávamos nos fazer presentes e prestar algum tipo de 
apoio). Podemos finalizar assim, colocando em foco que já não somos os mesmos, e sim outros de nós. Provocados por alterizações produzidas em cada encontro realizado.

\section{REFERÊNCIAS}

ALBUQUERQUE, Eliane Borges Correia de. Conceituando alfabetização e letramento. In: SANTOS, Carmi Ferraz; MEDONÇA, Márcia. (Org.).

Alfabetização e Letramento: conceitos e relações. Belo Horizonte: Autêntica, 2007. p.11-22

ALICE no País das Maravilhas. Direção de Tim Burton. Estados Unidos: Walt Disney Pictures, 2010. 1 Dvd.

BARROS, Laura Pozzana de; KASTRUP, Virgínia. Cartografar é acompanhar processos. In: PASSOS, Eduardo; KASTRUP, Virgínia; ESCÓSSIA, Liliana da.(Org.). Pistas do método da cartografia: pesquisa-intervenção e produção de subjetividade. Porto Alegre: Sulina, 2015. p. 52-75.

BARDIN, Laurence. Análise de conteúdo. São Paulo: Edições 70, 2011.

CARROLL, Lewis. Aline no país das maravilhas. São Paulo: Universo dos Livros, 2014.

DIMENSTEIN, Magda. A cultura profissional do psicólogo e o ideário individualista: implicações para a prática no campo da assistência pública à saúde. Estudos de Psicologia, Natal, v.5, n.1, p. 95-121, 2000.

ESCÓSSIA, Liliana da; KASTRUP, Virgínia. O conceito de coletivo como superação da dicotomia indivíduo-sociedade. Psicologia em Estudo, Maringá, v. 10, n. 2, p. 295-304, maio./ago. 2005.

GUATTARI, Félix. Caosmose: um novo paradigma estético. Tradução de Ana Lúcia de Oliveira e Lúcia Cláudia Leão. Rio de Janeiro: Ed. 34, 1992.

Da produção de subjetividade. In: PARENTE, André. (Org.). ImagemMáquina. . Rio de Janeiro, ed. 34, 1993. p. 177-191.

FERREIRA, Sandra Patrícia Ataíde; DIAS, Maria da Graça Bompastor Borges. A leitura, a produção de sentidos e o processo inferencial. Psicologia em

Estudo, Maringá, v. 9, n. 3, p. 439-448, set./dez. 2004.

LEFTA, Vilson J. Aspectos da leitura: uma perspectiva psicolinguística. Porto Alegre: Sagra: DC Luzzatto, 1996. 
LEONTIEV, A. N. Actividad, consciencia y personalidad. Buenos Aires: Ciencia del hombre, 1978.

PAULON, Simone Mainieri; ROMAGNELI, Roberta Carvalho. Pesquisaintervenção e cartografia: melindres e meandros metodológicos. Estudos e Pesquisas em Psicologia, Rio de Janeiro, ano 10, n. 1, p.85-102, 2010.

VALENCIA, Maria Cristina Palhares; MAGALHÃES, Michelle Cristina. Biblioterapia: síntese das modalidades terapêuticas utilizadas pelo profissional. Biblos: Revista do Instituto de Ciências Humanas e da Informação, Rio Grande, v. 29, n. 1, p. 5-27, 2015.

ZENELLA, Andréa Vieira. Sujeito e alteridade: reflexões a partir da psicologia histórico-cultural, Psicologia \& Sociedade, Belo Horizonte, v. 17, n. 2, p. 99104, maio/ago., 2005.

\title{
Title
}

A dialogue between real life and the children's literature: a reading experience in the perspective of the production of meaning

\begin{abstract}
:
Introduction: Over time, the term reading has been conceptualized in a polysemic way, and its meaning depends on the approach to be understood. In this study, we focus on the conciliatory perspective. In this perspective, text and reader are in a constant interaction. Thus, reading is interacting with the text and producing meanings. Based on this meaning, we seek in our study an interlocution with the technique of bibliotherapy, understood as a therapy through books.

Objective: To recaracterize the illness process of an infant oncological patient through the use of bibliotherapy, in order to defocalize the disease with the insertion of the ludic through children's literature.

Methodology: The research is of a qualitative nature, classified in terms of procedures as an Intervention Research. It has descriptive characteristics and is associated with the cartographic method. With a female child (11 years old), diagnosed with a malignant pelvic neoplasm, in an advanced stage. We also used drawing as a dialog promoter between the professionals involved in intervention and the patient.

Results: The proposed reading allowed our interlocutor to not only experience her history in her own way, but also resignify it.

Conclusions: We can conclude by emphasizing that we are no longer the same, but others of us, provoked by "othering" produced in each encounter.
\end{abstract}

Keywords: Alice in Wonderland. Bibliotherapy. Children's Literature. Cartographic Method. Intervention Research. 


\section{Titulo}

Un dialogo entre la vida real y la literatura infanto-juvenil: una experiencia de lectura en la perspectiva de la producción de sentidos

\section{Resumen:}

Introducción: A lo largo del tiempo, el término lectura ha sido conceptuado de forma polisémica y su significado depende del enfoque a ser entendido. En el estudio se ha centrado la perspectiva conciliadora. En este, texto y lector se encuentran en constante interacción. Así, leer es interactuar con el texto, producir significados. Partiendo de esta acepción, es que buscamos en nuestro estudio una interlocución con la técnica de la biblioterapia, entendida como una terapia por intermedio de libros.

Objetivo: Resignificar el proceso de enfermedad de una paciente oncológica infantil a través de la biblioterapia, de forma a des focalizar la enfermedad con la inserción de lo lúdico a través de la literatura infantil.

Metodología: La investigación tiene carácter cualitativo, se clasifica como procedimientos de investigación-intervención. Posee características descriptivas y asociado al método cartográfico. Teniendo como protagonista, una niña (11 años), diagnosticada con una neoplasia pélvica de carácter maligno en etapa avanzada. Todavía, se utilizó el dibujo como promotor de diálogo entre los profesionales involucrados en la intervención y la paciente.

Resultados: La lectura propuesta le permitió a nuestra interlocutora no sólo vivenciar su historia a su modo, como también resignificarla.

Conclusiones: Así podemos acabar, colocando en foco que ya no somos los mismo, pero si otros. Provocados por alteraciones producidas en cada encuentro realizado.

Palabras clave: Alicia en el país de las maravillas. Biblioterapia. Literatura infantojuvenil. Método cartográfico. Investigación-intervención.

Recebido: 10.03 .2017

Aceito: 10.11.2017 